\title{
Research on Logistic Operation of Public 3A Grade hospitals
}

\author{
Yuan Zhan ${ }^{1}$, Yang Liu ${ }^{1}$, Shiqing Zou ${ }^{1 *}$ \\ ${ }^{1}$ Wuhan Univ, Zhongnan Hosp of Wuhan University, Wuhan 430071, PR China
}

\begin{abstract}
Research on hospital logistics management is conducive to improving the efficiency of logistics operations and promoting the economic development of the hospital. In order to solve the problem of logistics management affected by a large number of uncertainties and multi-state factors, a set of 12-factor research index system was constructed from three aspects: basic skills, element skills, and task skills, and at the same time, the level of evaluation indicators was determined. In the interval, a research method of hospital logistics management based on cloud model is proposed. And according to Monte Carlo simulation, find out specific sensitive factors. Finally, the effectiveness and feasibility of the method is verified through the logistic operation and maintenance examples of 4 Grade-A public hospitals in Wuhan.
\end{abstract}

\section{Introduction}

With the continuous deepening of China's medical and health industry reforms and the diversification of medical needs and services, as the basis of hospital clinical, teaching and scientific research, logistics support is directly related to the normal operation and healthy development of the medical system [1]. In accordance with the requirements of the State Council's 2017 "Guiding Opinions on Establishing a Modern Hospital Management System", we will improve the logistics management system, explore the "one-stop logistics" service model of hospitals, and promote the socialization of hospital logistics services. This puts forward more levels, higher quality and more diverse requirements for hospital logistics management. Therefore, in order to meet the requirements of hospital logistics support service under the new medical reform situation, the present situation of hospital logistics operation is scientifically analyzed and studied, and its operation and maintenance benefits are comprehensively evaluated and effectively improved. In order to ensure the comprehensive competitiveness of hospitals has important practical significance.

Zhou et al. used internet technology and thinking for the continuous improvement of hospital logistics. And the "Internet plus" also achieved integrated efficiency and real-time connectivity [2]. Li et al. implement the standardization of hospital logistics management through performance-based management methods, so as to obtain better job performance and standardized job process reengineering. Baed on Changgung-featured management system [3]. Wu et al. improved the level of hospital logistics in terms of standardization of operations, refined equipment maintenance, and daily skill training [4]. The above scholars analyzed the hospital logistics management through different methods, summarized the main existing problems from different angles, and made a useful attempt for the hospital logistics management research. However, hospital logistics management is a complex and systematic problem with many influencing indicators, which are independent and mutually restrictive. It is difficult to fully reflect this complex and uncertain process by using simple methods or qualitative evaluations.

As a qualitative and quantitative interchange model, the Cloud Model can handle uncertain data while taking into account the randomness of the evaluation process and the ambiguity of things themselves [5]. Currently, this method has been widely used in the fields of finance [6], engineering [7], and enterprise management [8]. This paper proposes a cloud model-based hospital logistics management research method. Based on the establishment of an evaluation index system and grade division, the efficiency level of the logistics operation management of each case hospital is obtained, and effective improvement measures are taken to provide the hospital with quality, safety, and safety. Effective and convenient medical services provide logistical service guarantee.

\section{Method}

\subsection{Cloud Model}

The Cloud Model theory is a quantitative and qualitative uncertainty transformation model proposed by Academician Li Deyi, which combines the fuzziness in fuzzy set theory with the randomness in probability theory [9]. The concept $\mathrm{C}$ expressed by the three mathematical characteristics of expected value $(E x)$ 、 entropy $(E n)$ and hyper entropy $(H e)$ as a whole. Ex represents the typical sample point that best represents the qualitative concept $\mathrm{C}$ in the number domain space. En reflects the three

* Corresponding author: dabailiu@whu.edu.cn 
uncertainties of $\mathrm{C}$, namely, the ambiguity of the distribution range of the cloud drop group accepted by $\mathrm{C}$ in the number domain, the probability density of the cloud drop group language value, and the correlation between ambiguity and randomness. He refers to the measurement of the uncertainty of all points in this space that represent the language value. Through the three mathematical characteristics of the cloud, the distribution of cloud drops is generated, so as to realize the conversion from qualitative concepts to quantitative values. surname.

Step 1. The cloud model is constructed. According to formula (1), the model is constructed for each grade corresponding to the $V 1 \sim V 12$ of the research index, that is, the eigenvalue $(E x, E n 、 H e)$ is determined, in which the $\mathrm{s}$ is constant.

$$
\left\{\begin{array}{l}
E x=\frac{C_{\text {max }}+C_{\text {min }}}{2} \\
E n=\frac{C_{\text {max }}-C_{\text {min }}}{6} \\
H e=s
\end{array}\right.
$$

Step 2. By calculating the membership degree of each index eigenvalue to each level of cloud model, the eigenvalue belongs to the membership degree of the jth security level. Where is the actual value of the index, and $E x, E n$, and $s$ are the three parameters of the corresponding grade cloud model.

$$
\begin{aligned}
& \mu_{i j}=\exp \left[-\frac{\left(x-E x_{i j}\right)^{2}}{2\left(E n_{i j}\right)^{2}}\right] \\
& E n_{i j}{ }^{\prime}=E n_{i j}+s_{i j} \times \operatorname{randn}()
\end{aligned}
$$

Step 3. According to formula (4), the index weight is multiplied by the degree of membership. For example, the first four are multiplied by the weight to get the management level of the secondary index "basic skills", and the last four are multiplied by their respective weights to get the management level of the "element skills". The last four indicators are multiplied by their respective weights to get the "task skills" research level.

$$
K_{i}=\sum_{j=1}^{5} w_{i j} \bullet \mu_{i j}
$$

\subsection{Evaluation method}

\subsubsection{Evaluation system construction}

Pubic hospital logistics management involves many aspects and links such as medical equipment, doctorpatient services, material circulation, financial management, hospital assets and environment, and has many characteristics such as multiple types of equipment and facilities, strong scope of services, and large social impact. It needs to be covered The management of people, the monitoring of finances, and the operation of things are a complex and detailed integrated service system. Based on extensive literature review, this paper seeks the opinions of a number of third-level A public hospital management experts, and combines hospital logistics evaluation standards and management objectives to build 12 of the three aspects of basic ability, element ability and task ability [10]. The index management research system is shown in Figure 1.

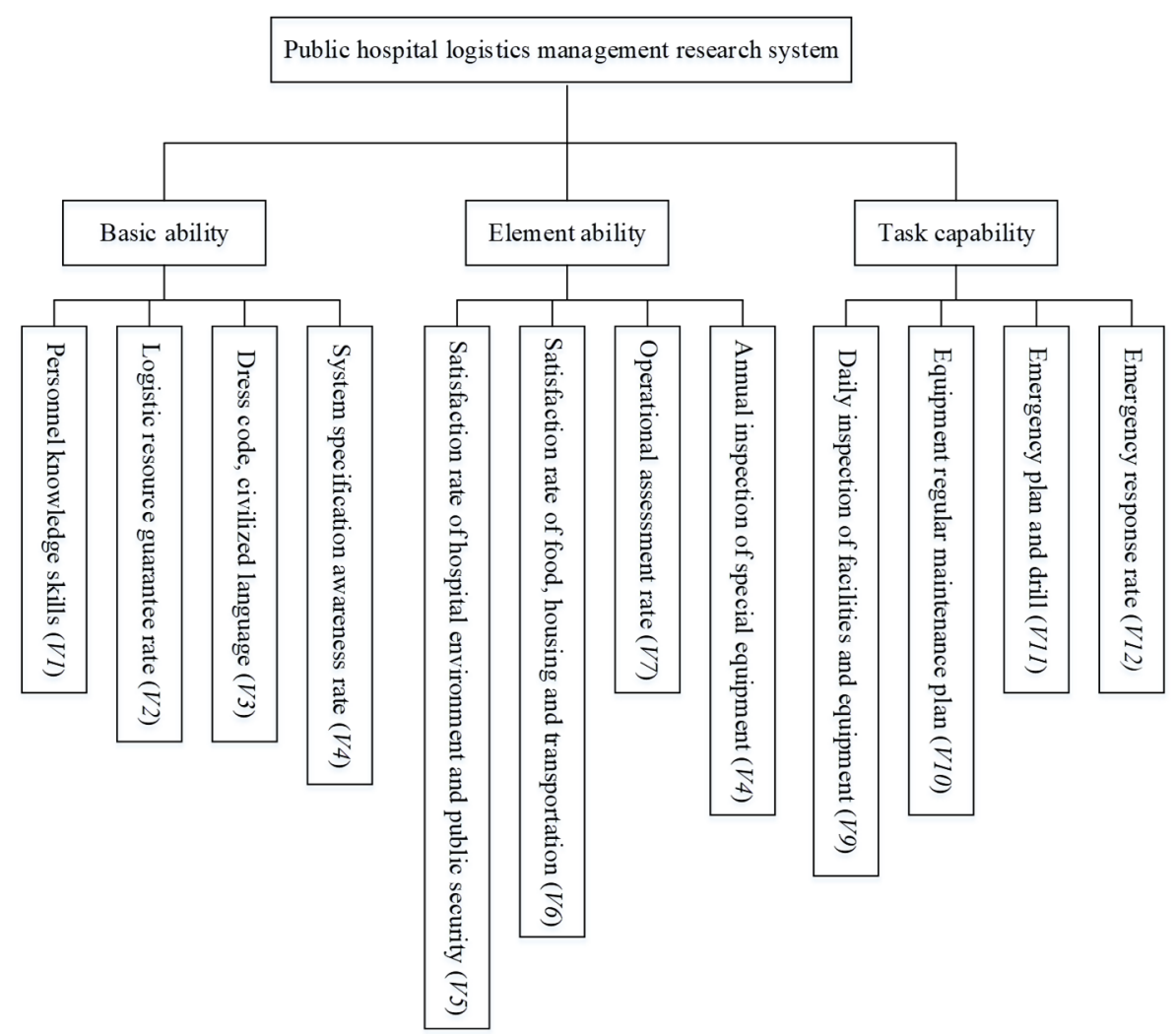

Fig1. Public hospital logistics management research system. 


\subsection{2 valuation system construction}

As the key content of management research, whether the weight distribution of its indicators is reasonable will directly affect the accuracy and scientificity of the evaluation results of operation management. In this paper, the entropy method is used to calculate the weight of the research index [11]. The essence of this method is to make full use of the information utility value of the index factors. The higher the utility value, the greater the importance of evaluation, which can avoid the subjectivity of weight assignment and the problem of measurement "uncertainty".

The calculation steps are as follows. First, we determine the existing index decision matrix $A=\left(d_{k j}\right)_{\mathrm{m} * \mathrm{n}}$. With reference to the given weight calculation formula (5), formula (6) can be used to calculate and determine $p_{k j}$. According to the information theory using formula (7), the information entropy of indicator $B_{j}$ can be obtained as $H_{j}$. When $p_{k j}=0$, specify $p_{k j} \ln p_{k j}=0$. Use formula (8) to find the weight $w_{j}$ of index $B_{j}$ :

$$
\begin{gathered}
W=\left(w_{1}, w_{2}, \ldots, w_{n}\right)^{T} \\
p_{k j}=d_{k j} / \sum_{k=1}^{m} d_{k j}, k=1,2, \ldots, m ; j=1,2, \ldots n \\
H_{j}=-\frac{1}{\ln m} \sum_{k=1}^{m} p_{k j} \ln p_{k j}, j=1,2, \ldots, \mathrm{n} \\
w_{j}=\frac{1-H_{j}}{\sum_{j=1}^{n}\left(1-H_{j}\right)}, j=1,2, \ldots, \mathrm{n}
\end{gathered}
$$

Finally, the weights of the secondary and tertiary indicators in the management research system are obtained through the entropy method, as shown in Table 1.

Table1. Research index weights at all levels.

\begin{tabular}{clcccl}
\hline Index & Weight & Index & Weight & Index & Weight \\
Basic ability & 0.1349 & $V 3$ & 0.1876 & $V 8$ & 0.1891 \\
Element ability & 0.4815 & $V 4$ & 0.2136 & $V 9$ & 0.3502 \\
Task capability & 0.3836 & $V 5$ & 0.3145 & $V 10$ & 0.2856 \\
V1 & 0.2753 & $V 6$ & 0.2856 & $V 11$ & 0.1485 \\
$V 2$ & 0.3235 & $V 7$ & 0.2108 & $V 12$ & 0.2157
\end{tabular}

\subsubsection{Management level and scope}

reform documents and related documents, the development status of logistics management is divided into four levels: A, B, C, and D. After calculation and analysis, The conversion of qualitative dimensions into quantitative dimensions corresponds to " $0 \sim 1 "$ ", "1 $\sim 2$ ", In order to comprehensively study the status and development trend of hospital operation and management, combined with the National Health and Family Planning Commission's public hospital logistics management "2 3", and "3 or more", as shown in Table 2.

Table2. Classification of logistics management research.

\begin{tabular}{ccccc}
\hline Potential level & Grade A & Grade B & Grade C & Grade D \\
Basic ability & Excellent & Good & General & Poor \\
Interval value & {$[0,1)$} & {$[1,2)$} & {$[2,3)$} & {$[3,+\infty)$} \\
\hline
\end{tabular}

According to the national hospital management standards and policies, as well as the logistic management status of many tertiary first-class hospitals in Wuhan and past data summary, 12 of the indicator data are obtained through questionnaire surveys, skill tests, and inspection statistics. Similarly, the research indicators are divided into four levels from excellent to bad: A (excellent state), B (good state), C (general state), and D (poor state). Determine the level and interval division of each logistics management index: $\left[\mathrm{C}_{\min }, \mathrm{C}_{\max }\right], V 1 \sim V 12$ are three-level indexes. as shown in Table 3.

Table3. Operation evaluation index and classification.

\begin{tabular}{ccccc}
\hline \multirow{2}{*}{$\begin{array}{c}\text { Serial } \\
\text { number/Index }\end{array}$} & \multicolumn{4}{c}{ Classification } \\
\cline { 2 - 4 } & Grade A & Grade B & Grade C & Grade D \\
\hline$V 1$ & $(85,100]$ & $(70,85]$ & $(60,70]$ & $(45,60]$ \\
$V 2$ & $(90,100]$ & $(80,90]$ & $(70,80]$ & $(55,70]$ \\
$V 3$ & $(80,100]$ & $(70,80]$ & $(60,70]$ & $(45,60]$ \\
$V 4$ & $(85,100]$ & $(75,85]$ & $(60,75]$ & $(0,60]$
\end{tabular}




\begin{tabular}{ccccc}
$V 5$ & $(85,100]$ & $(75,85]$ & $(60,75]$ & $(0,60]$ \\
$V 6$ & $(90,100]$ & $(80,90]$ & $(70,80]$ & $(50,70]$ \\
$V 7$ & $(85,100]$ & $(75,85]$ & $(60,75]$ & $(0,60]$ \\
$V 8$ & $(80,100]$ & $(70,80]$ & $(60,70]$ & $(40,60]$ \\
$V 9$ & $(18,24]$ & $(12,18]$ & $(6,12]$ & $(0,6]$ \\
$V 10$ & $(80,100]$ & $(70,80]$ & $(60,70]$ & $(45,60]$ \\
$V 11$ & $(85,100]$ & $(70,85]$ & $(60,70]$ & $(50,60]$ \\
$V 12$ & $(95,100]$ & $(85,95]$ & $(75,85]$ & $(60,75]$ \\
\hline
\end{tabular}

\section{Case study}

By looking up the logistics management data of four Grade 3A general hospitals in Wuhan in 2018, we use the method of this paper to study the logistics status of four hospitals to verify the feasibility and effectiveness of the method.

According to the 4 logistic management levels and ranges, the characteristic values of 12 indicators are obtained by formula (1), and the cloud model corresponding to the evaluation interval (48 in total) is established. The $s$ is taken as 0.05 . The Ex, En, and $s$ of each indicator are shown in Table 4.

Table4. Logistics management data of four public hospitals in 2018.

\begin{tabular}{ccccc}
\hline Index & Hospital 1 & Hospital 2 & Hospital 3 & Hospital 4 \\
\hline$V 1$ & $(92.5,2.5,0.05)$ & $(77.5,2.5,0.05)$ & $(65,1.67,0.05)$ & $(52.5,2.5,0.05)$ \\
$V 2$ & $(95,1.67,0.05)$ & $(85,1.67,0.05)$ & $(75,1.67,0.05)$ & $(62.5,2.5,0.05)$ \\
$V 3$ & $(90,3.33,0.05)$ & $(75,1.67,0.05)$ & $(65,1.67,0.05)$ & $(52.5,2.5,0.05)$ \\
$V 4$ & $(92.5,2.5,0.05)$ & $(80,1.67,0.05)$ & $(67.5,2.5,0.05)$ & $(30,0,0.05)$ \\
$V 5$ & $(92.5,2.5,0.05)$ & $(80,1.67,0.05)$ & $(67.5,2.5,0.05)$ & $(30,0,0.05)$ \\
$V 6$ & $(95,1.67,0.05)$ & $(85,1.67,0.05)$ & $(75,1.67,0.05)$ & $(60,3.33,0.05)$ \\
$V 7$ & $(92.5,2.5,0.05)$ & $(80,1.67,0.05)$ & $(67.5,2.5,0.05)$ & $(30,0,0.05)$ \\
$V 8$ & $(90,3.33,0.05)$ & $(75,1.67,0.05)$ & $(65,1.67,0.05)$ & $(50,3.33,0.05)$ \\
$V 9$ & $(21,1,0.05)$ & $(15,1,0.05)$ & $(9,1,0.05)$ & $(3,0,0.05)$ \\
$V 10$ & $(90,3.33,0.05)$ & $(75,1.67,0.05)$ & $(65,1.67,0.05)$ & $(52.5,2.5,0.05)$ \\
$V 11$ & $(92.5,2.5,0.05)$ & $(77.5,2.5,0.05)$ & $(65,1.67,0.05)$ & $(55,1.67,0.05)$ \\
$V 12$ & $(97.5,0.83,0.05)$ & $(90,1.67,0.05)$ & $(80,1.67,0.05)$ & $(67.5,2.5,0.05)$ \\
\hline
\end{tabular}

According to formulas (2) and (3), the cloud model of each index grade corresponds to the membership degree of each operating state, and then the logistic operation and

Table5. Logistic operation and maintenance level of the four hospitals.

\begin{tabular}{ccc}
\hline Evaluation interval & Hospital & Logistics operation and maintenance in 2018 \\
1.7779 & Hospital 1 & Good \\
2.5343 & Hospital 2 & General \\
3.1269 & Hospital 3 & Poor \\
0.9874 & Hospital 4 & Excellent \\
\hline
\end{tabular}

\section{Case study}

This paper introduces the cloud model theory into the research of hospital logistics management for the first time, and establishes a comprehensive research system of logistics management with 12 indicators at three levels, which overcomes the subjectivity and one-sidedness of indicator selection, and divides the management level into four different levels. It uses cloud model methods to study the development trends of various indicators. Then, through the logistics operation management examples of 4 tertiary A hospitals in Wuhan in 2018, the logistics management level of each hospital is basically consistent with the actual situation. In this way, scientific supervision and targeted management can realize the maximization of guarantee capabilities and guarantee benefits, and provide safe, efficient and professional logistics services for the hospital. 


\section{References}

1. Liu, X.Y., Zhang, Q.L., Xu, Y., Wu, X.Y., Wang, X.F. (2020) Trend analysis of medical expenses in Shenzhen after China's new health-care reforms. International Journal of Health Planning and Management 35, 760-772.

2. Zhou, F., Yu, H., Chen, H. (2017) Practice of the " Internet plus" subliminal in hospital logistics management. Chinese Journal of Hospital Administration 33, 926-929.

3. Li, F., Jia, C., Zhou, Y. (2017) Application strategy of standard time management in hospital logistics. Chinese Journal of Hospital Administration 33, 856858.

4. Wu, P., Li, N., Li, S., Zhao, K., Zhao, G. (2019) Practice in engineering works: logistics management of Changgung feature. Chinese Journal of Hospital Administration 35, 242-246.

5. Zhang, L.M., Wu, X.G., Chen, Q.Q., Skibniewski, M.J., Zhong, J.B. (2015). Developing a cloud model based risk assessment methodology for tunnelinduced damage to existing pipelines. Stochastic Environmental Research and Risk Assessment 29, 513-526.

6. Liu, S. (2018) Transshipment Strategies Between Eshops in Network Shopping Mall Based on Cloud Model. Control Engineering of China 25, 1428-1433.

7. Zhang, L.M., Wu, X.G., Zhu, H.P., AbouRizk, S.M. (2017). Perceiving safety risk of buildings adjacent to tunneling excavation: An information fusion approach. Automation in Construction 73, 88-101.

8. Meng, B., Niu, E., Kuang, H., Luo, J. (2018). An evaluation model and empirical research on CSR based on cloud model. Science Research Management 39, 139-150.Thompson, J.N. (1984) Insect Diversity and the Trophic Structure of Communities. In: Ecological Entomology. New York. pp. 165-178.

9. Wu, X., Wu, K., Shen, M., Zhang, L., Zhang, W.,(2016). Evaluation on structure health and safety of operating tunnel based on cloud model. Journal of Safety Science and Technology 12, 73-79.

10. Wang, B., Chen, Z., Zhuo, L., Li, J., Qian, W., Bao, D.(2019). Explorations and practices of lean management for hospital logistics materials management. Chinese Journal of Hospital Administration 35, 238-241.

11. Li, H., Liu, T., Wu, X., Chen, Q.(2020) Enhanced Frequency Band Entropy Method for Fault Feature Extraction of Rolling Element Bearings. Ieee Transactions on Industrial Informatics 16, 5780-5791. 